\title{
DEVELOPMENT OF EVALUATION SYSTEM OF COASTLINE RESOURCE IN DAFENG
}

\author{
Chen Ming, Ph.D. ${ }^{1,2}$ \\ Xu Changxin, Prof. Dr. ${ }^{1}$ \\ Chen Hongquan, Prof. Dr. ${ }^{3}$ \\ ${ }^{1}$ Business School, Hohai University, Nanjing 211100, China \\ ${ }^{2}$ Gulf Coast Research \& Education Center, University of Florida, Wimauma 33598, United States \\ ${ }^{3}$ School of Urban Planning, Yancheng Teachers University, Yancheng 224007, China
}

\begin{abstract}
Coastline is one type of valuable non-renewable resources. From the perspective of economic theory, it can gather population, promote traffic construction, and then improve the level of international trade. The research object of this paper is the coastline resource in Dafeng area. Firstly, we have a brief summary of the existing coastline evaluation literature, then introduce the location and natural attributes of the coastline resources in Dafeng. Following that, the Analytic Hierarchy Process (AHP) model is used to build the economic evaluation index system based on the characteristics of coastline in Dafeng. Specially, this index system consists of 6 factors, and a total of 41 detailed indicators were chosen including water depth, GDP, etc. On this basis, we use the assignment method to quantify the weight of each index, and calculate the comprehensive score of coastline resource by using the YAAHP software. The final conclusion is as follows: The total score of economic evaluation of coastline resource in Dafeng is 0.87. Therefore, the coastline resource in Dafeng will eventually be constructed a unique coastal economic zone, where the implemented port industrial projects will include shipbuilding, logistics, mechanical processing etc.
\end{abstract}

Keywords: Coastline; Analytic Hierarchy Process; Evaluation System

\section{INTRODUCTION}

As coastline resource is an important natural resource, scientific evaluation is a prerequisite for the efficient use of this valuable resource. Therefore, research on coastline especially the evaluation of it has been a hot topic in academic circles for a long time. However, in the existing research on coastline resource evaluation, researchers mainly use GIS or engineering index system methods to study it based on geography theory. And there are few studies focus on the comprehensive utilization of coastline resource from the perspective of economics. Though, some scholars have done the research on coastline using some special economic methods in recent years, they still ignore the economic characteristics of coastline resource. Besides, the main objects of these studies are port coastline resource, few of them are aimed at silt coastline $[1,2,3,4,5]$. To solve the above drawbacks, this paper constructs the economic evaluation index system which meets the characteristics of coastline resource. Then, using the AHP method to get the weight of various indicators, and evaluate the utilization of coastline finally.

The research object of this paper is the coastline resource in Dafeng area. Obviously, this coastline is located in Dafeng City. In this place, the depth of the water is about $15 \mathrm{~m}$ and it is stable. Meanwhile, the length of the coastline is about $55 \mathrm{~km}$, and the width of $-15 \mathrm{~m}$ isobath is a bout $3-4 \mathrm{~km} .100000$ ton-ships can enter this area. The east side of Dafeng coastline is the small sand, it is a natural barrier and can prevent the 


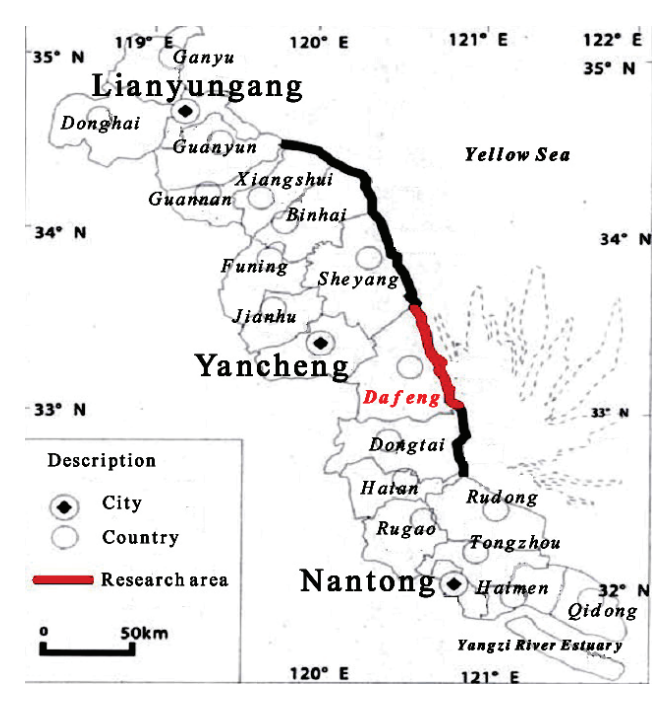

Fig.1. The location of coastline resource in Dafeng

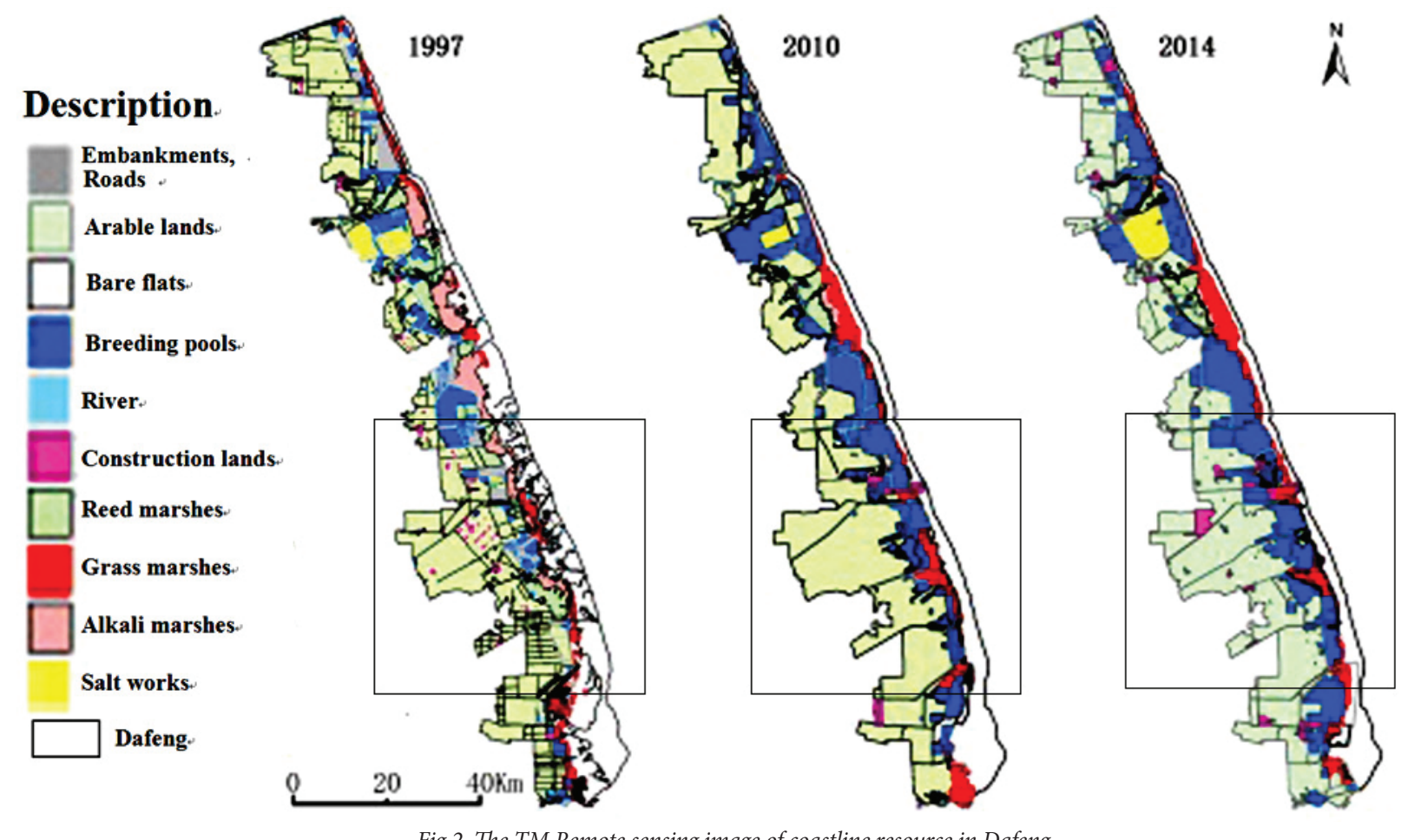

Fig.2. The TM Remote sensing image of coastline resource in Dafeng

coastline from the erosion of wind and waves. The average velocity of small tide is $0.56-1.2 \mathrm{~m} / \mathrm{s}$ and the average velocity of large tide is $0.83-1.26 \mathrm{~m} / \mathrm{s}$. The coastline in Dafeng area is not frozen all year round and can be used for more than 300 days per year. The location and the TM Remote sensing image of coastline resource in Dafeng are shown in Fig.1 and Fig. 2 respectively.

\section{METHODS}

\section{THE PRINCIPLE OF THE MODEL}

In this paper, the Analytic Hierarchy Process (AHP) method is used to evaluate the development of coastal resource. The model of AHP method covers the following 5 steps:

\section{The establishment of hierarchical model}

The problem is divided into three specific levels according AHP method: the first level is the Target Hierarchy, it 


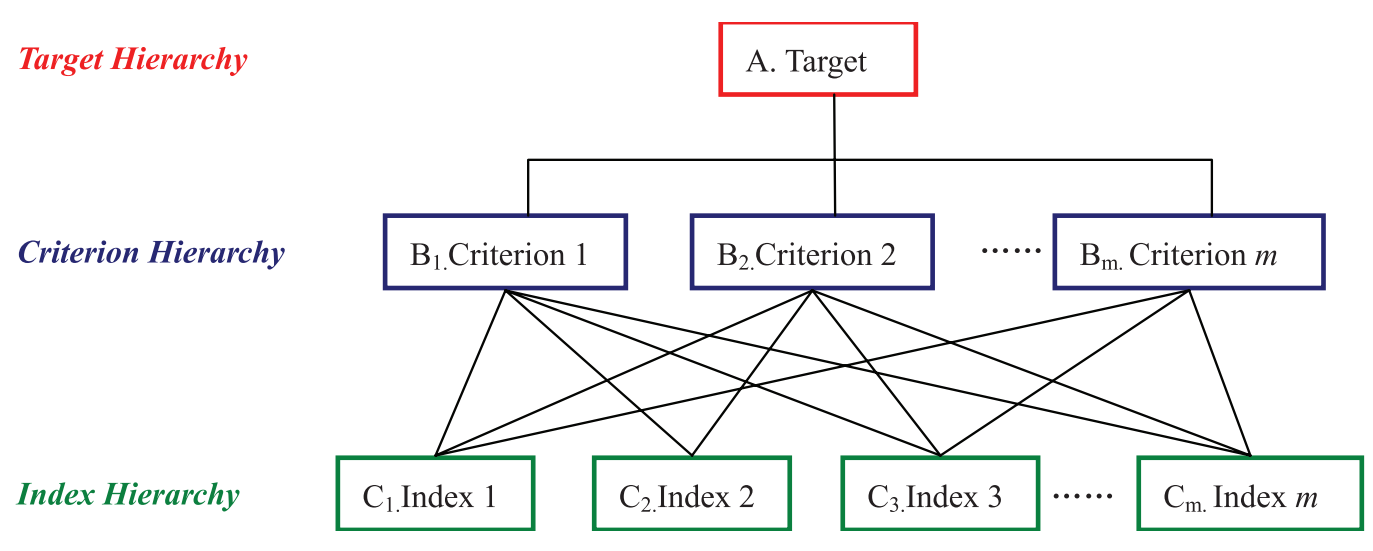

Fig.3. The schematic diagram of the AHP model

represents the goal to be resolved; the second level is the Criterion Hierarchy, it will refine the target to the relevant secondary indicators; the third level is the Index Hierarchy, it will further refine the detailed indicators. The schematic diagram of the AHP model is shown in Fig.3.

\section{The construction of judgment matrix}

The judgment matrix is used to determine the relative importance of each element in the hierarchy (for an element of the previous hierarchy), the number 1-9 and its reciprocal usually used to present the value of it. The meaning of the value of the judgment matrix is shown in Tab.1:

Tab.1. The meaning of the value of the judgment matrix

\begin{tabular}{|c|c|}
\hline The value & \multicolumn{1}{|c|}{ The meaning of the value } \\
\hline 1 & The factor $i$ is as important as the factor $j$ \\
\hline 3 & $\begin{array}{c}\text { The factor } i \text { is slightly more important than } \\
\text { the factor } j\end{array}$ \\
\hline 5 & $\begin{array}{c}\text { The factor } i \text { is significantly more important } \\
\text { than the factor } j\end{array}$ \\
\hline 7 & $\begin{array}{c}\text { The factor } i \text { is very more important than the } \\
\text { factor } j\end{array}$ \\
\hline 9 & $\begin{array}{c}\text { The factor } i \text { is extramly more important } \\
\text { than factor } j\end{array}$ \\
\hline $2,4,6,8$ & Half of the value of the above situation \\
\hline reciprocal & $\begin{array}{c}\text { The reciprocal representation of the above } \\
\text { situation }\end{array}$ \\
\hline
\end{tabular}

3. The single sequence of the hierarchy

The single sequence of the hierarchy is the process of determining the weight of the sequence of importance of the elements associated with it (for an element in the previous hierarchy). Its specific method of operation is to calculate the eigenvalues and eigenvectors of the judgment matrix. For the judgment matrix $A$, the eigenvalues and eigenvectors satisfying $A W=\lambda \max W$ are calculated. Where $\lambda \max$ is the largest eigenvalue of $A, W$ is the normalized eigenvector corresponding to $\lambda \max$, the component $W i$ of $W$ is the weight value of the corresponding element single sequence[6,7].

For the judgment matrix $A$, if $a_{i j}=a_{i j} a_{i k}(i, j, k=1,2,3, \ldots, n)$ is satisfied, it is said to be fully consistent. But this situation is generally impossible to achieve, so it is necessary to conduct a consistency check on the basis of the single sequence of the hierarchy. Then the consistency index $C I$ of the measurement matrix $A$ have to be calculated ( $n>1$ order square matrix), where $C I=\left(\lambda_{\max }-n\right) /(n-1)$. When $C I=0, A$ is called fully consistent. And there is the greater the $C I$, the worse the consistency of $A$. The consistency ratio $C R$ and the average random consistency index $R I$ are introduced to test whether the judgment matrix $A$ has a satisfactory consistency. The values of $R I$ are shown in Tab.2.

Tab.2. The values of $R I$

\begin{tabular}{|c|c|c|c|c|c|c|c|c|c|}
\hline 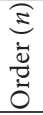 & 1 & 2 & 3 & 4 & 5 & 6 & 7 & 8 & 9 \\
\hline$R I$ & 0 & 0 & 0.58 & 0.9 & 1.12 & 1.24 & 1.32 & 1.41 & 1.45 \\
\hline
\end{tabular}

When $C R<0.1$, the judgment matrix $A$ has a satisfactory consistency; otherwise, when $C R \geq 0.1$, the consistency of the judgment matrix $A$ can not be accepted, and it needs to be adjusted until it is satisfied.

4. The total sequence of the hierarchy

Calculate the same level of all factors for the highest level (the total target) relative importance of the sorting weights, called the total ranking of the hierarchy. If the previous hierarchy $A$ contains the $m$ elements $A_{1}, A_{2}, \ldots, A_{m}$, the value of the total sequence of the hierarchy $A$ are $a_{1}, a_{2}, \ldots, a_{m}$. The weights value of the $n$ elements $B_{1}, B_{2}, \ldots, B_{n}$ of the next hierarchy $B$ are $b_{1 j}, b_{2 j}, \ldots, b_{n j}$ respectively (where $b_{i j}=0$, if $B_{i}$ is not associated with $A_{j}$ ), then the value of the total sequence of the hierarchy $B$ are shown in Tab.3. 


\begin{tabular}{cccccc}
\hline \multirow{2}{*}{ Sequence } & $A_{1}$ & $A_{2}$ & $\ldots$ & $A_{m}$ & $\begin{array}{c}\text { The toal sequence of } \\
\text { the hierarchy }\end{array}$ \\
\cline { 2 - 5 } & $a_{1}$ & $a_{2}$ & $\ldots$ & $a_{m}$ & $\sum_{j=1}^{m} a_{j} b_{1 j}$ \\
$B_{1}$ & $b_{11}$ & $b_{12}$ & $\ldots$ & $b_{1 m}$ & $\sum_{j=1}^{m} a_{j} b_{2 j}$ \\
$B_{2}$ & $b_{21}$ & $b_{22}$ & $\ldots$ & $b_{2 m}$ & $\ldots$ \\
$\ldots$ & $\ldots$ & $\ldots$ & $\ldots$ & $\ldots$ & $\sum_{j=1}^{m} a_{j} b_{n j}$ \\
$B_{n}$ & $b_{n 1}$ & $b_{n 2}$ & $\ldots$ & $b_{l m}$ & \\
\hline
\end{tabular}

If $\sum_{i=1}^{n} \sum_{j=1}^{m} a_{j} b_{i j}=1$, then its total sequence of the hierarchy is the normalized normal vector.

\section{Consistency test}

The calculation steps for consistency test of the total sequence of the hierarchy are as follows:

$$
\begin{gathered}
C I=\sum_{j=1}^{m} a_{j} C I_{j} \\
R I=\sum_{j=1}^{m} a_{j} R I_{j} \\
C R=\frac{C I}{R I}
\end{gathered}
$$

When $C R<0.1$, the judgment matrix $A$ has a satisfactory consistency; otherwise, when $C R \geq 0.1$, the consistency of the judgment matrix $A$ can not be accepted, and it needs to be adjusted until it is satisfied $[8,9,10]$.

\section{FORMULA OF THE MODEL}

In this paper, the quantification of indicators of coastline resource utilization model is complicated. Some of the indicators can be quantified directly, such as the natural conditions in the model of climate conditions. It can be expressed by Equation (4). A satisfactory value (upper limit) and an unsatisfactory value (lower limit) can be determined according to the actual situation.

$$
W_{k i}=\left(P_{k i}-P_{i \min }\right) /\left(P_{i \max }-P_{i \min }\right)
$$

In Equation (4), $W_{k i}{ }^{--}$the quantitative score of the index $i$ of the coastline $k, 0<W_{k i}<1$;

$P_{k i}{ }^{--}$the direct value of the index $i$ of the coastline $k$;
$P_{i \max }{ }^{--}$the upper limit of the satisfaction value of the index $i$ of the coastline;

$P_{i \min }{ }^{--}$the lower limit of the satisfaction value of the index $i$ of the coastline.

The value of most qualitative indicators can not be quantified directly. In this paper, the expert scoring method is used to quantify these indicators by setting the most satisfactory value (upper limit) to 1 , the most dissatisfied value (lower limit) is 0. Specifically, the satisfaction value is $0.9-1$, the satisfaction value is $0.6-0.8$, the general satisfaction value is $0.4-0.5$, the dissatisfaction value is $0-0.3$.On this basis, the multi-factor comprehensive evaluation model is established according to the Equation (4) $[11,12,13]$. This model is used to evaluate the utilization of the coastline resource, and the specific formula is given in Equation (5).

$$
S_{k}=\sum_{i=1}^{m} Z_{i} W_{k i}
$$

In Equation (5), $S_{i}$-- the total score of the coastline $k, 0<S_{i}<1$; $Z_{i}$-- the total weight value of the index $i$ of the coastline, $0<Z_{i}<1$;

$W_{k i}{ }^{--}$the quantitative score of the index $i$ of the coastline $k, 0<W_{k i}<1$.

\section{RESULTS}

The economic evaluation index system of coastline resource includes 6 factors (ie. Natural Factors, Policy \& Regulatory Factors, Economic Development Factors, Social Service Factors, Environmental Resource Factors, Traffic Regional Factors), which contain 41 detailed indicators. The indicator system is shown in Fig.4.

In this paper, AHP method is used to assign value to 41 refinement indexes and operate by YAAHP software $[14,15]$. And the final score of the economic evaluation of Dafeng coastline resource is caculated according the Equations (4) and (5). The results are shown in Tab.4. 


\section{Target Hierarchy}

\section{Economic Evaluation Index System of Coastline Resource}

Criterion Hierarchy

$\left\{\begin{array}{l|l|}\hline \text { 1. Natural Factors }\left(B_{1}\right) \\ \hline \text { 2. Policy \& Regulatory Factors }\left(B_{2}\right) \\ \hline \text { 3. Economic Development Factors }\left(B_{3}\right) \\ \hline \text { 4. Social Service Factors }\left(B_{4}\right) \\ \hline \text { 5. Environmental Resource Factors }\left(B_{5}\right) \\ \hline \text { 6. Traffic Regional Factors }\left(B_{6}\right) \\ \hline\end{array}\right.$

Fig.4. The schematic diagram of the indicator system

The coastline resource is classified as four different grades according to the final score and the port coastline level classification criteria[11-14]. They are shown in Table 4: (1) the best economic effect of coastline resource $A(0.7 \leq A \leq$ $1)$; (2) the excellent economic effect of coastline resource $B$ $(0.6 \leq B<0.7)$; (3) the general economic effect of coastline resource $C(0.5 \leq C<0.6)$; (4) the poor economic effect of coastline resource $D(0 \leq D<0.5)$.

The economic evaluation of coastline resource in Dafeng is shown in Fig.5.

\begin{tabular}{|l|l|}
\multicolumn{3}{c|}{ Index Hierarchy } \\
Criterion Hierarchy
\end{tabular}

\begin{tabular}{|l|l|lr|}
\hline $\begin{array}{c}\text { Policy \& } \\
\text { Regulatory } \\
\text { Factors }\left(\mathbf{B}_{2}\right)\end{array}$ & & $\mathrm{C}_{9}$ : The reform and opening policies & 0.0189 \\
\hline
\end{tabular}

\begin{tabular}{|c|c|c|}
\hline & $\mathrm{C}_{14}$ Direct income & 0.00408 \\
\hline & $\mathrm{C}_{15:}$ Transformation investment & 0.00459 \\
\hline \multirow{6}{*}{$\begin{array}{c}3 . \\
\text { Economic } \\
\text { Developmen } \\
\text { t Factors } \\
\left(B_{3}\right)\end{array}$} & $\mathrm{C}_{16} \mathrm{GDP}$ & 0.03878 \\
\hline & $\mathrm{C}_{17}$ : The hinterland city type & 0.01590 \\
\hline & $\mathrm{C}_{18}$ : Industrial park scale and enterprises number & 0.01869 \\
\hline & $\mathrm{C}_{19}$ : Gross agricultural output & 0.00702 \\
\hline & $\mathrm{C}_{20}$ : Gross Industrial Product & 0.01224 \\
\hline & $\begin{array}{l}\mathrm{C}_{21} \text { : The gross domestic product of the service ind } \\
\text { total Trade volume }\end{array}$ & $\begin{array}{r}\text { stry and } \\
0.01232\end{array}$ \\
\hline
\end{tabular}

Tab.4. The classification criteria for shoreline resources

\begin{tabular}{|l|c|}
\hline \multicolumn{1}{|c|}{ The results of the evaluation } & Score \\
\hline $\begin{array}{l}\text { 1. The best economic effect of coastline } \\
\text { resource - } A\end{array}$ & $0.7 \leq A \leq 1$ \\
\hline 2. $\begin{array}{l}\text { The excellent economic effect of } \\
\text { coastline resource - } B\end{array}$ & $0.6 \leq B<0.7$ \\
\hline 3. $\begin{array}{l}\text { The general economic effect of } \\
\text { coastline resource -- } C\end{array}$ & $0.5 \leq C<0.6$ \\
\hline 4. $\begin{array}{l}\text { The poor economic effect of } \\
\text { coastline resource -- } D\end{array}$ & $0 \leq D<0.5$ \\
\hline
\end{tabular}
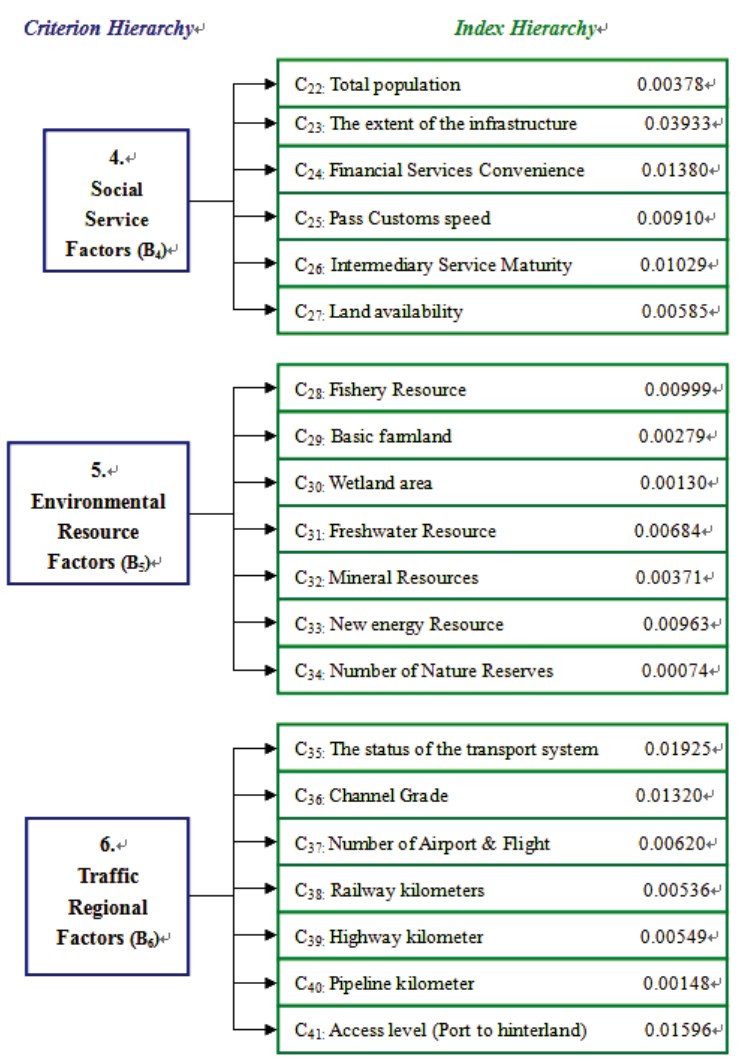

Fig.5. The economic evaluation of coastline resource in Dafeng 


\section{CONCLUSIONS}

In this paper, the Natural Factors are the most important prerequisites for the use of the coastline resource according to the above results. The total score of coastline sedimentation weight is 0.09018 , which is the most important detailed factor in all. The Policy \& Regulatory Factors play a significant role in the development of the coastline. Among them, the score of whether the development and utilization of coastline conforms to the regional development plan is 0.0888 and the score of the national regional industrial support policy is 0.0611 . These two detailed factors are the key factors that affect the implementation of coastline development.

The comprehensive score of the coastline resource in Dafeng is 0.87. According to the classification standard, it belongs to Class $A$ ( the best economic effect of coastline resource $A(0.7 \leq A \leq 1))$ and it can be used to construct the port. And the implemented port industrial projects includes shipbuilding, logistics, mechanical processing. The coastline resource in Dafeng will eventually be constructed a unique coastal economic zone.

\section{ACKNOWLEDGMENTS}

This research was financially supported by: (1)National Natural Science Foundation of China (No: 51279058 \& No: 41471456); (2)The Major Program of University Natural Science Foundation of Jiangsu Province (No: 14KJA170006); (3)Graduate students' Program of Scientific Research and Innovation in Jiangsu Province (No: KYZZ15_0158); (4)The Joined PhD student program funded by China Scholarship Council (No: 201506710057).

\section{REFERENCES}

5. 1. Peter G.: Approximation schemes for parallel machine scheduling with non-renewable resources. European Journal of Operational Research. No.1,Vol.258, 2017, p.113-123.

6. 2. Gregory S., Steffen R.: Dynamic convexification within nested Benders decomposition using Lagrangian relaxation: An application to the strategic bidding problem. European Journal of Operational Research. No,2,Vol.257, 2017, p.669-686.

7. 3. Paul A., Omheni R.: A globally and quadratically convergent primal-dual augmented Lagrangian algorithm for equality constrained optimization. Optimization Methods \& Software. No.1,Vol.32, 2017, p.1-21.

8. 4. Curtis F.E.: Adaptive augmented Lagrangian methods: algorithms and practical numerical experience. Optimization Methods \& Software. No.1,Vol.31, 2016, p.157-186.
9. 5. Rob H.: Non-renewable resources in the long run. Journal of Economic Dynamics and Control. No.1,Vol.71, 2016, p.1-20.

10. 6. Derpich I., Sepulveda J.: Lagrangian Formulation for Energy-efficient Warehouse Design. Intenational Journal ofcomputers communications \& control. No.1,Vol.12, 2017, p.41-52.

11. 7. Zhang Z.: Environmental and Natural Resource Economics. High Education Press, Beijing, 2008.

12. 8. Josep M.: The optimal utilization proportion of external beam radiotherapy in European countries: An ESTROHERO analysis. Radiotherapy and Oncology. No.1,Vol.116, 2015, p.38-44.

13. 9. Curtis F.E.: Adaptive augmented Lagrangian methods: algorithms and practical numerical experience. Optimization Methods \& Software. No.1,Vol.31, 2016, p.157-186.

14. 10. Chen M., Xu C.X.: Study of Urban Economic and Environmental System Coordinated Development Measure. International Journal of Applied Environmental Sciences. No.4,Vol.9, 2014, p.1603-1613.

15. 11. Katie W.: Optimal utilization of a breast care advanced practice clinician. The American Journal of Surgery. No.6,Vol.208, 2014, p.1054-1059.

16. 12. Michael L.: Optimal Sequential Plantings of Corn and Soybeans Under Price Uncertainty. American Journal of Agricultural Economics. No.3,Vol.97, 2015, p.855-878.

17. 13. Chen M., Xu C.X.: Study on rural water pollution causes and prevention of Jiangsu province. Journal of Chemical and Pharmaceutical Research. No.12,Vol.5, 2013, p.532-536.

18. 14. Wang B.Q., Cao T.T., Chen M.: (2014). Study on the Problems and Countermeasures of Metropolis Water Source Protection. BioTechnoogy: An Indian Journal. No.12,Vol.10, 2014, p.1203-1208.

19. 15. Derpich I., Sepulveda J.: Lagrangian Formulation for Energy-efficient Warehouse Design. Intenational Journal ofcomputers communications \& control. No.1,Vol.12, 2017, p.41-52. 


\section{CONTACT WITH THE AUTHOR}

Chen Hongquan, Prof. Dr.

e-mail:hhcm1008@126.com

School of Urban Planning Yancheng Teachers University 224007 Yancheng

CHINA 